\title{
Faculty intent to engage in interprofessional education
}

This article was published in the following Dove Press journal:

Journal of Multidisciplinary Healthcare

18 April 2013

Number of times this article has been viewed

\author{
Maria Olenick' \\ Lois Ryan Allen² \\ 'College of Nursing and Health \\ Science, Florida International \\ University, Miami, FL, USA; \\ ${ }^{2}$ School of Nursing, Widener \\ University, Chester, PA, USA
}

Correspondence: Maria Olenick College of Nursing and Health Science, Foreign Educated Physician Program, Florida International University, 3000 NE I5 I st Street, ACII-203,

North Miami, FL 33I8I, USA

Tel +l 3059194420

$\mathrm{Fax}+\mathrm{I} 3059195209$

Email molenick@fiu.edu
Background: This descriptive correlational and comparative study explored health-care faculty (HCF) attitudes toward interprofessional education (IPE) and interprofessional healthcare teams, HCF perceptions of subjective norms, the influence of subjective norms on HCF intent to engage in IPE, and HCF intent to engage in IPE. In addition, differences among seven disciplines of HCF were explored.

Methods: Nursing, medicine, pharmacy, physical therapy, occupational therapy, physician assistants, and social work faculty were identified. Stratified random sampling was used to ensure that the population surveyed was representative of the target population. The total sample for this study included 439 HCF from the seven identified health-care professions in the US. Data collection included measures of attitudes toward IPE and attitudes toward interprofessional health-care teams. Subjective norms were measured using two 7-point rating scales. Intent to engage in IPE was measured using a 10-point rating scale.

Results: There were no significant differences among HCF groups regarding attitudes toward IPE or interprofessional health-care teams. Administrative faculty reported greater intent to engage in IPE than teaching faculty. HCF who were currently in or had previously engaged in IPE reported greater intent to engage in or continue to engage, and had higher attitude and subjective norm scores than faculty without IPE experience. The combination of perceived pressure from school administrators and attitudes toward IPE was the best predictor of intent to engage in IPE.

Conclusion: IPE has the potential to influence patient quality of care and lead to better working relationships between health-care providers. HCF are more likely to engage in IPE when they believe their school's administrators think they should engage in IPE and when they have positive attitudes toward IPE.

Keywords: interdisciplinary, multidisciplinary, IPE, teamwork, health-care

\section{Introduction}

The purpose of this study was to examine health-care faculty (HCF) intent to engage in interprofessional education (IPE). The Institute of Medicine (IOM) issued a report entitled To Err is Human: Building a Safer Health System..$^{1}$ This report indicated that as many as 98,000 preventable deaths occur per year. Lack of interprofessional collaboration and effective communication are attributed to these preventable errors that cause more death than motor vehicle accidents, breast cancer, and AIDS. In 1999, the committee recommended that those who work in interprofessional teams should be trained in interprofessional teams. 
Three additional IOM reports concluded that all health-care student education should focus on patient-centered care, which is promoted by IPE. The 2001 report, Crossing the Quality Chasm: A New Health System for the 21st Century, ${ }^{2}$ recommended that all health-care professional students should receive education and training in interdisciplinary teams related to interdisciplinary care. The 2003 report, Health Professions Education: A Bridge to Quality Care, ${ }^{3}$ listed five competencies that concern all health-care disciplines: (1) provide patient-centered care, (2) work in interdisciplinary teams, (3) employ evidence-based practice, (4) apply quality improvement, and (5) utilize informatics. Based on these reports that reflect over 10 years of literature review and workshops to identify concerns and develop strategies to improve patient care, the IOM concluded that health-care professionals must deliver competent patient-centered care in interdisciplinary teams and identified IPE as an essential element in the education of health-care professionals.

The most recent IOM report (2010), The Future of Nursing: Leading Change, Advancing Health, ${ }^{4}$ calls for and specifically cites interprofessional collaboration for nursing. This vision of the future of health care in the US defines interprofessional collaboration as the norm. The IOM states the role of nurses is to design and implement early and continuous IPE through collaborative classroom and clinical opportunities. IPE can only be achieved through committed collaborative partnerships across professions. Collaborative cultures in this IOM vision are vital in sustaining and continuing improvements in quality of care.

IPE was first identified as an essential health-care education element in 1978 by the World Health Organization (WHO). In 1984, the WHO recommended that health-care professional students engage in shared learning to improve their skills in solving complex health and social care problems, and deliver health care based on common values, knowledge, and skills. In 1988, the WHO assessed IPE efforts, identified IPE gaps, identified IPE organizations, identified research contributions to IPE, and initiated development of a conceptual framework in a multiprofessional education report. More recently, WHO announced the launch of its study group on IPE and collaborative practice, consisting of 25 experts on education, practice, and policy from around the world ${ }^{5}$ and in 2010 published the Framework for Action on Interprofessional Education and Collaboration. ${ }^{6}$ Therefore, IPE is not a new concept to health-care professionals. However, it is a topic of recent interest and extensive discussion and debate because it prepares health-care professions to work in dynamic, challenging, contemporary health systems where mutual respect and collaborative care contribute to improving patient outcomes. ${ }^{7}$ As such, IPE stands as an alternative to more traditional hierarchical models of both health-care professional education and health-care delivery.

Quality health-care is affected by how well health-care professionals work together and may also be influenced by attitudes toward IPE and interprofessional health-care teams (IPHCTs). Various professions are often unaware of the practices of one another. ${ }^{8}$ Problems with interprofessional communication can have a negative influence on patient care and services. Williams et $\mathrm{al}^{9}$ documented the negative impact of interprofessional communication problems on patient-care issues, including delays in patient care, wasted staff time, and serious adverse patient consequences. Rosenstein and O'Daniel ${ }^{10}$ found that disruptive behaviors that affect health-care teams negatively may lead to poorquality patient outcomes and adverse events for patients. Due to the negative impact on patient care and services that interprofessional tensions can create, improved collaboration, improved communication, and team building have been advocated. Interprofessional teams improve patient safety and quality of care. ${ }^{11}$

IPE is an andragogical interactive experiential learning and socialization process. ${ }^{12}$ An extensive literature search and concept analysis by Olenick et al revealed that "IPE occurs when two or more members of a health-care team, who participate in either patient assessment and/or management, learn with, from, and about each other as they collaboratively focus on patient-centered care and achieving optimal health outcomes. In IPE, knowledge and value sharing occur within and across disciplines" (p6). ${ }^{12}$ Effective interprofessional collaboration, established through IPE, may diminish negative attitudes and stereotypes and promote a focus on effective working relationships for optimal patient-focused care through facilitation and optimization of collaborative patient care and safety. ${ }^{13}$

Accrediting bodies for the health-care profession education programs currently require evidence of IPE curriculum integration and expectations for health-care professionals to function in effective teams. Many HCF have not been educated this way, and HCF attitudes toward IPE, IPHCTs, and interprofessional learning in academic settings are largely unexplored. Literature regarding faculty attitudes and familiarity with IPE is lacking, with most available IPE literature originating from Europe or Canada.

Despite IOM directives, WHO recommendations, current literature, and accreditation requirements for healthprofession education programs, most health-care professional 
students in the US do not receive specific education about being a member of a collaborative team. In the US, education of health-care professional students continues to be discipline-specific and continues in a silo approach at most educational institutions. ${ }^{14,15}$ In this silo approach, health professions are isolated within their own disciplines, or intellectual walls, living within their own departments, professional associations, professional journals, and belief systems. ${ }^{8}$

\section{Aims of the study}

The aims of this descriptive correlational and comparative study were to explore HCF attitudes toward IPE and IPHCTs, subjective norm (SN) influence on HCF intent to engage in IPE, and HCF intent to engage in IPE. This study also explored differences among types of HCF from various health-care profession education programs.

\section{Theoretical basis of this study: theory of reasoned action}

The theory of reasoned action (TRA) by Fishbein and Ajzen, first published in 1975, ${ }^{16}$ explains the links among attitudes, intention, and behavior. The three main components of TRA are attitudes, SNs, and behavioral intentions. The combination of attitudes and SNs predicts behavioral intentions. ${ }^{16}$ TRA has been found to predict intentions and behaviors well. ${ }^{17}$ There is no feedback or extraneous influences between attitudes and SNs in prediction of intention, but it is the sum of these that influence and predict behavioral intent.

Fishbein and Ajzen ${ }^{16}$ defined attitude as a "person's location on a dimension of affect or evaluation" (p53). Attitudes are developed based on the strength of a person's beliefs and on positive or negative personal feelings about performing a behavior. In TRA, belief is "location on a probability dimension that links an object and an attribute" (p53). ${ }^{16}$ Beliefs and feelings are based on a person's perception of how important or unimportant something is.

SNs are the perceived social pressures to perform a behavior. ${ }^{18} \mathrm{SNs}$ are a person's perception of what someone of influence wants them to do. SNs consist of both internal and external influences. Internal influences include skills, abilities, information, and emotions. External influences include situational or environmental factors, such as any conditions that contribute to the way a person acts or reacts, such as information acquisition and physical and social surroundings.

Intentions are dimensions of probability that link a person's intentions to action. Behaviors are "observable acts" (p13). ${ }^{16}$ Behavioral intentions are guided by attitudes and SNs.
According to TRA, behavioral intention predicts behavior but does not directly cause it to occur, since behavior may be affected by three factors: volitional control, consideration of the relationship between attitudes and behavior at the same level, and change in attitudes over time.

Variables in this study represented constructs of TRA theory. When IPE was viewed within TRA, HCF attitudes and SNs were positioned to affect HCF intentions and ultimately behavior to engage in IPE in the education of healthcare professional students.

\section{Methods \\ Sample}

HCF were selected via Internet searches of the health-care programs of colleges and universities throughout the US. A stratified, random, proportionate sample of $10 \%$ of programs was compiled and separated according to the four US Census Bureau regions (Northeast, Midwest, South, and West $)^{19}$ and based on availability of publicly available faculty email addresses on the Internet on the school or health-care education program (eg, nursing program) website. The total number of programs for each health-care discipline in each region is presented in Table 1.

We identified nursing schools that offered baccalaureate and higher-degree programs in nursing and were accredited by the Commission on Collegiate Nursing Education or the National League of Nursing Accrediting Commission. Allopathic medical schools (MD) that were accredited by the Liaison Committee on Medical Education, pharmacy schools that were accredited by the Accreditation Council for Pharmacy Education, physical therapy schools that were accredited by the Commission on Accreditation in Physical

Table I Number of health-discipline programs per Census Bureau region and type of program and number randomly selected for study

\begin{tabular}{llllll}
\hline $\begin{array}{l}\text { Type of } \\
\text { program }\end{array}$ & $\begin{array}{l}\text { Northeast } \\
\mathbf{n}(\mathbf{1 0})\end{array}$ & $\begin{array}{l}\text { Midwest } \\
\mathbf{n}(10 \%)\end{array}$ & $\begin{array}{l}\text { South } \\
\mathbf{n}(10 \%)\end{array}$ & $\begin{array}{l}\text { West } \\
\mathbf{n}(10 \%)\end{array}$ & Total \\
\hline NU & $165(17)$ & $226(23)$ & $264(26)$ & $98(10)$ & $753(76)$ \\
MD & $31(3)$ & $32(3)$ & $50(5)$ & $16(2)$ & $129(13)$ \\
PH & $22(2)$ & $26(3)$ & $46(5)$ & $23(2)$ & $117(12)$ \\
PT & $56(6)$ & $58(6)$ & $62(6)$ & $28(3)$ & $204(21)$ \\
OT & $46(5)$ & $40(4)$ & $47(5)$ & $19(2)$ & $152(16)$ \\
PA & $47(5)$ & $34(3)$ & $51(5)$ & $22(2)$ & $154(15)$ \\
SW & $47(5)$ & $53(5)$ & $76(8)$ & $42(4)$ & $218(22)$ \\
Total & $414(43)$ & $469(47)$ & $596(60)$ & $248(25)$ & $1727(175)$ \\
programs in & & & & & \\
each region & & & & & \\
\hline
\end{tabular}

Abbreviations: NU, nursing; MD, allopathic medical schools; $\mathrm{PH}$, pharmacy; PT, physical therapy; OT, occupational therapy; PA, physician assistant; SW, social work. 
Therapy Education, occupational therapy schools that were accredited by the Accrediting Council for Occupational Therapy Education, physician assistant programs that were accredited by the Accreditation Review Commission for the Physician Assistant, and social work programs that were accredited by the Council on Social Work Education were also identified. Only programs that offered a minimum of a bachelor's degree or higher in these disciplines were included in this study.

From the 175 randomly selected programs, we accessed each program's website and searched for publicly available email addresses of faculty. Study-inclusion criteria were included in the demographic data-collection portion of the online survey. Only HCF who were employed in one of the seven health-care disciplines were included in this study. Those who held a master's degree or above, who were full-time, and who had professorial rank (full professor, associate professor, or assistant professor) were invited to complete the survey. These inclusion criteria were selected since it is more probable that only full-time professors with an advanced degree would have a voice in determining curriculum and opportunity related to engaging in IPE.

It was expected that the original random selection of $10 \%$ of programs in each Census Bureau region would be sufficient to acquire the 231 subjects required for this study. Nursing met its required 33 subjects very early on in the data collection, but the six other health-care disciplines lagged behind, despite us following Dillman et al's tailored design method. ${ }^{20}$ Therefore, another $10 \%$ of all health-care programs, except nursing, were randomly selected and sent out for a total of $20 \%$ of all programs nationwide, excluding nursing, which remained at the $10 \%$ rate. Subjects were not asked on the demographic data form which school they were associated with, as a measure to maintain confidentiality.

An a priori power analysis determined the minimum total sample size of 231 which was required for this study. Sample size was calculated using Sample Power version 2 (IBM, Armonk, NY, USA). ${ }^{21}$ Effect size, significance level, and power were all considered. A medium effect size, a significance level of 0.05 and a power of 0.80 were used to compute the power analysis.

The actual sample for this study included $439 \mathrm{HCF}$ from the seven health-care professions nationwide. Emails were sent out to faculty in 274 schools from the stratified random sample of health-care professional education programs across the US. Most of the respondents in the total sample $(n=439)$ were nurses $(n=191)$. Most were female who held doctoral degrees. Most were full-time, permanent, teaching faculty with an average age of 49.79 years, an average of 23.66 years experience as a health professional, and 14.09 years experience as a health-professional educator. Most were currently or had previously implemented IPE. Details of the descriptive statistics of demographic variables are presented in Tables 2 and 3. In Table 2, the number of responses for each faculty group does not always equal the number of subjects in the groups, due to missing data.

\section{Measures}

A demographic data form was used to collect information for the purpose of describing study subjects. Two research instruments that were adapted for assessing faculty attitudes by Curran et $\mathrm{al}^{22}$ were used to measure the attitude variables. The first instrument was adapted by Curran et al from Parsell and $\mathrm{Bligh}^{23}$ and measures attitudes towards IPE. The second instrument was adapted by Curran et al from Heinemann, Schmitt, and Farrell, ${ }^{24}$ and measures attitudes towards health-care teams. These instruments were chosen for use in this study because they were designed specifically to measure faculty attitudes toward IPE and IPHCTs, which were the research variables in this study. Table 4 presents Cronbach's alpha internal consistency reliability coefficients for the two attitude scales for each group of HCF. Cronbach's alpha ranged from 0.89 to 0.93 on the Attitudes Toward IPE instrument and from 0.85 to 0.90 on the Attitudes Toward IPHCTs instrument among HCF groups. Construct validity was established for both instruments by Curran et al. ${ }^{22}$

SNs were measured using two single-item, continuous, 7-point, magnitude rating scales. The first scale stated "My faculty colleagues think I should or should not engage in IPE." The second scale stated "My school's administrators think I should or should not engage in IPE." The rating scales ranged from 1 (I should not) to 7 (I should).

Intent to engage in IPE was measured using a single-item, continuous, 10-point, magnitude-rating scale. Subjects were asked how likely they were to engage in IPE within the next 3 years. The rating scale ranged from 1 (not at all likely to engage in IPE within the next 3 years) to 10 (very likely to engage in IPE within the next 3 years).

\section{Procedures}

Upon institutional review board approval, an email message was sent to each of the HCF, asking them to complete an online survey. Dillman et al's tailored design method was used in an attempt to achieve a predicted response rate of $80 \% .^{20}$

HCF employed within the selected 10\%-20\% healthdiscipline programs within the four Census Bureau regions received emails with an online Survey Monkey 
Table 2 Frequencies and percentages of sample characteristics

\begin{tabular}{|c|c|c|c|c|c|c|c|c|c|c|c|c|c|c|}
\hline \multirow[t]{2}{*}{ Variable and categories } & \multicolumn{2}{|c|}{$\begin{array}{l}\text { NU } \\
(n=191)\end{array}$} & \multicolumn{2}{|c|}{$\begin{array}{l}\text { MD } \\
(n=38)\end{array}$} & \multicolumn{2}{|c|}{$\begin{array}{l}\mathrm{PH} \\
(\mathrm{n}=46)\end{array}$} & \multicolumn{2}{|c|}{$\begin{array}{l}P T \\
(n=50)\end{array}$} & \multicolumn{2}{|c|}{$\begin{array}{l}\text { OT } \\
(n=40)\end{array}$} & \multicolumn{2}{|c|}{$\begin{array}{l}\text { PA } \\
(n=38)\end{array}$} & \multicolumn{2}{|c|}{$\begin{array}{l}\text { SW } \\
(n=36)\end{array}$} \\
\hline & $\mathbf{n}$ & $\%$ & $\mathbf{n}$ & $\%$ & $\mathbf{n}$ & $\%$ & $\mathbf{n}$ & $\%$ & $\mathbf{n}$ & $\%$ & $\mathbf{n}$ & $\%$ & $\mathbf{n}$ & $\%$ \\
\hline \multicolumn{15}{|l|}{ Sex } \\
\hline Female & 182 & 95.8 & 16 & 43.2 & 28 & 60.9 & 33 & 66.0 & 31 & 77.5 & 22 & 57.9 & 27 & 75.0 \\
\hline Male & 8 & 4.2 & 21 & 56.8 & 18 & 39.1 & 17 & 34.0 & 9 & 22.5 & 16 & 42.1 & 9 & 25.0 \\
\hline \multicolumn{15}{|l|}{ Highest degree } \\
\hline Bachelor's & & & 1 & 2.6 & & & & & & & & & & \\
\hline Master's & 57 & 30.2 & I & 2.6 & I & 2.2 & 7 & 14.0 & II & 27.5 & 22 & 59.5 & 3 & 8.3 \\
\hline Doctorate & 132 & 69.8 & 36 & 94.7 & 45 & 97.8 & 43 & 86.0 & 29 & 72.5 & 15 & 40.5 & 33 & 91.7 \\
\hline \multicolumn{15}{|l|}{ Teach at level } \\
\hline Bachelor's & 135 & 70.7 & 4 & 10.5 & 1 & 2.2 & & & 6 & 15.0 & 2 & 5.3 & & \\
\hline Master's & 93 & 48.7 & 6 & 15.8 & 2 & 4.3 & I & 2.0 & 39 & 97.5 & 38 & 100 & 33 & 91.7 \\
\hline Doctorate & 41 & 21.5 & 38 & 100 & 46 & 100 & 50 & 100 & 5 & 12.5 & & & 8 & 22.2 \\
\hline \multicolumn{15}{|l|}{ Employment status } \\
\hline Part-time & 8 & 4.3 & 4 & 11.4 & & & 2 & 4.1 & 3 & 7.5 & 3 & 8.1 & 2 & 5.6 \\
\hline Full-time & 178 & 95.7 & 31 & 88.6 & 46 & 100 & 47 & 95.9 & 37 & 92.5 & 34 & 91.9 & 34 & 94.4 \\
\hline \multicolumn{15}{|l|}{ Appointment status } \\
\hline Permanent & 173 & 91.1 & 35 & 92.1 & 44 & 95.7 & 48 & 96.0 & 36 & 90.0 & 34 & 89.5 & 31 & 86.1 \\
\hline Temporary & 17 & 8.9 & 3 & 7.9 & 2 & 4.3 & 2 & 4.0 & 4 & 10.0 & 4 & 10.5 & 5 & 13.9 \\
\hline \multicolumn{15}{|l|}{ Faculty position } \\
\hline Teaching faculty & 161 & 85.2 & 32 & 88.9 & 38 & 84.4 & 42 & 85.7 & 30 & 78.9 & 24 & 64.9 & 30 & 85.7 \\
\hline Administrative faculty & 28 & 14.8 & 4 & II.I & 7 & 15.6 & 7 & 14.3 & 8 & 21.1 & 13 & 35.1 & 5 & 14.3 \\
\hline \multicolumn{15}{|l|}{ Tenure appointment } \\
\hline Tenured & 53 & 27.9 & 3 & 8.1 & 18 & 39.1 & 17 & 35.4 & 12 & 30.0 & 6 & 16.2 & 18 & 50.0 \\
\hline Tenure track & 52 & 27.4 & 3 & 8.1 & 7 & 15.2 & 9 & 18.8 & 9 & 22.5 & 4 & 10.8 & 8 & 22.2 \\
\hline Nontenure track & 85 & 44.7 & 31 & 83.8 & 21 & 45.7 & 22 & 45.8 & 19 & 47.5 & 27 & 73 & 10 & 27.8 \\
\hline \multicolumn{15}{|l|}{ Currently implementing IPE } \\
\hline Yes & 86 & 45.0 & 27 & 71.1 & 27 & 58.7 & 37 & 74.0 & 23 & 57.5 & 29 & 76.3 & 19 & 52.8 \\
\hline No & 105 & 55.0 & 11 & 28.9 & 19 & 41.3 & 13 & 26.0 & 17 & 42.5 & 9 & 23.7 & 17 & 47.2 \\
\hline \multicolumn{15}{|l|}{ Previously implemented IPE } \\
\hline Yes & 90 & 47.6 & 24 & 63.2 & 29 & 63.0 & 31 & 64.6 & 26 & 65.0 & 28 & 73.7 & 21 & 58.3 \\
\hline No & 99 & 52.4 & 14 & 36.8 & 17 & 37.0 & 17 & 35.4 & 14 & 35.0 & 10 & 26.3 & 15 & 41.7 \\
\hline Academic appointment & & & & & & & & & & & & & & \\
\hline Full professor & 35 & 18.3 & 8 & 21.1 & 18 & 39.1 & 6 & 12.0 & 2 & 5.0 & 3 & 7.9 & 9 & 25.0 \\
\hline Associate professor & 45 & 23.6 & 9 & 23.7 & 11 & 23.9 & 19 & 38.0 & 17 & 42.5 & 10 & 26.3 & 12 & 33.3 \\
\hline Assistant professor & 95 & 49.7 & 19 & 50.0 & 14 & 30.4 & 20 & 40.0 & 10 & 25.0 & 19 & 50.0 & 9 & 25.0 \\
\hline Clinical/instructor/lecturer & 13 & 6.8 & 1 & 2.6 & 3 & 6.5 & 5 & 10.0 & 9 & 22.5 & 6 & 15.8 & 3 & 8.3 \\
\hline Other & 3 & 1.6 & 1 & 2.6 & & & & & 2 & 5.0 & & & 3 & 8.3 \\
\hline Experience with IPE & & & & & & & & & & & & & & \\
\hline None & 62 & 33.0 & 7 & 18.4 & 10 & 21.7 & 9 & 18.4 & 8 & 20.0 & 5 & 13.2 & 7 & 19.4 \\
\hline$<$ I year & 27 & 14.4 & 5 & 13.2 & 4 & 8.7 & 6 & 12.2 & 3 & 7.5 & 5 & 13.2 & 3 & 8.3 \\
\hline $\mathrm{I}-2$ years & 31 & 16.5 & 7 & 18.4 & 8 & 17.4 & 8 & 16.3 & 7 & 17.5 & 10 & 26.3 & 6 & 16.7 \\
\hline $3-4$ years & 26 & 13.8 & 2 & 5.3 & 8 & 17.4 & 11 & 22.4 & 8 & 20.0 & 7 & 18.4 & 3 & 8.3 \\
\hline$>5$ years & 42 & 22.3 & 17 & 44.7 & 16 & 34.8 & 15 & 30.6 & 14 & 35.0 & 11 & 28.9 & 17 & 47.2 \\
\hline Experience with IPHCTs & & & & & & & & & & & & & & \\
\hline None & 27 & 14.1 & 7 & 18.4 & 7 & 15.2 & 5 & 10.0 & 2 & 5.0 & 4 & 10.5 & 4 & II.I \\
\hline$<$ I year & 10 & 5.2 & 2 & 5.3 & 3 & 6.5 & 2 & 4.0 & 1 & 2.5 & I & 2.6 & 1 & 2.8 \\
\hline $\mathrm{I}-2$ years & 17 & 8.9 & 5 & 13.2 & 5 & 10.9 & 3 & 6.0 & 2 & 5.0 & 5 & 13.2 & 5 & 13.9 \\
\hline $3-4$ years & 19 & 9.9 & I & 2.6 & 5 & 10.9 & 5 & 10.0 & I & 2.5 & 5 & 13.2 & 2 & 5.6 \\
\hline$>5$ years & 118 & 61.8 & 23 & 60.5 & 26 & 56.5 & 35 & 70.0 & 34 & 85.0 & 23 & 60.5 & 24 & 66.7 \\
\hline
\end{tabular}

Abbreviations: NU, nursing; MD, allopathic medical schools; PH, pharmacy; PT, physical therapy; OT, occupational therapy; PA, physician assistant; SW, social work; IPE, interprofessional education; IPHCTs, interprofessional health-care teams.

(http://www.surveymonkey.com) link. The email explained the study's purpose, procedures, risks and benefits, alternatives, costs, compensation, confidentiality, right to withdraw, contact information for the principal investigator, and link to the online survey. Participation was voluntary.
Informed consent was implied when a subject entered the survey website and submitted a completed survey. Subject anonymity and confidentiality were preserved, since there were no names attached to the online submitted surveys. Once a survey was submitted online, there was no way to 
Table 3 Descriptive statistics of sample age and experience

\begin{tabular}{|c|c|c|c|c|c|c|c|}
\hline Variables & $\begin{array}{l}\text { NU } \\
(n=191)\end{array}$ & $\begin{array}{l}\text { MD } \\
(n=38)\end{array}$ & $\begin{array}{l}\text { PH } \\
(n=46)\end{array}$ & $\begin{array}{l}\text { PT } \\
(n=50)\end{array}$ & $\begin{array}{l}\text { OT } \\
(n=40)\end{array}$ & $\begin{array}{l}\text { PA } \\
(n=38)\end{array}$ & $\begin{array}{l}S W \\
(n=36)\end{array}$ \\
\hline \multicolumn{8}{|l|}{ Age } \\
\hline Mean & 54.43 & 49.24 & 46.09 & 48.32 & 49.49 & 49.59 & 51.39 \\
\hline SD & 8.42 & 12.30 & 12.46 & 9.71 & 8.56 & 8.50 & 9.73 \\
\hline Range & $34-81$ & $31-73$ & $26-73$ & $28-68$ & $30-65$ & $31-67$ & $32-69$ \\
\hline \multicolumn{8}{|c|}{ Years experience as a health } \\
\hline \multicolumn{8}{|c|}{ professional } \\
\hline Mean & 31.06 & 20.90 & 20.74 & 23.28 & 24.67 & 22.66 & 22.29 \\
\hline SD & 9.14 & 13.04 & 14.46 & 10.82 & 10.10 & 8.29 & 11.05 \\
\hline Range & $7-58$ & $0-47$ & $0-52$ & $0-47$ & $1-46$ & $0-36$ & $0-45$ \\
\hline \multicolumn{8}{|c|}{ Years experience as a health } \\
\hline \multicolumn{8}{|c|}{ professional educator } \\
\hline Mean & 17.11 & 15.23 & 15.07 & 13.22 & 12.66 & 11.30 & 14.06 \\
\hline SD & 10.97 & 10.95 & 12.54 & 7.93 & 6.98 & 6.28 & 8.58 \\
\hline Range & $2-40$ & $2-40$ & $1-49$ & $1-33$ & $\mathrm{I}-28$ & $1-32$ & $2-38$ \\
\hline
\end{tabular}

Abbreviations: NU, nursing; MD, allopathic medical schools; PH, pharmacy; PT, physical therapy; OT, occupational therapy; PA, physician assistant; SW, social work; $\mathrm{SD}$, standard deviation.

withdraw from the study. Data were collected over a period of 1 month (January 2012).

\section{Results}

Analysis of data from the final sample $(\mathrm{n}=439)$ is discussed, summarized, and presented here. SPSS version 18 was used to compute all statistics for this study.

\section{Attitudes toward IPE and IPHCTs}

Attitudes toward IPE are faculty feelings and beliefs about IPE, and were measured by total scores on the Attitudes Toward IPE instrument adapted by Curran et al. ${ }^{22}$ Possible scores on the Attitudes Toward IPE instrument could range from 14 to 70 . Higher scores reflected more positive attitudes toward IPE. Nearly all ranges of scores were above the midpoint of possible scores of 42 and had means that ranged from 60.34 to 62.92 (standard deviation [SD] range 5.64-7.87) with multiple modes (ranging 54-70) within the seven HCF groups. Participants in this study scored high on their attitudes toward IPE, indicating all seven HCF groups had positive attitudes toward IPE.

Attitudes toward IPHCTs are faculty feelings and beliefs about IPHCTs. Attitudes toward IPHCTs were measured by total scores on the Attitudes Toward IPHCTs instrument adapted by Curran et al. ${ }^{22}$ Possible scores on the Attitudes
Toward IPHCTs instrument could range from 14 to 70 . Higher scores reflected more positive attitudes toward IPHCTs. Minimum scores for the Attitudes Toward IPHCTs fell below the midpoint of possible scores of 42 for four of the seven groups and had means that ranged from 54.88 to 58.36 (SD range 5.85-7.32), with multiple modes within the seven HCF groups. Participants in all seven HCF groups had positive attitudes toward IPHCTs; however, scores on attitudes toward IPHCTs were less positive than scores on attitudes toward IPE. Details of the descriptive statistical analysis for attitudes are presented in Table 5.

\section{Subjective norms and intentions to engage in IPE}

SNs are the influences that motivate HCF to engage in IPE. SNs are the perceived social pressures to perform a behavior, ${ }^{18}$ and were measured using two 7-point magnituderating scales to assess subjects' perceptions of whether they believed their faculty colleagues ( $\mathrm{SN}$ faculty colleagues) and their school's administrators (SN school's administrators) thought they should or should not engage in IPE. Possible scores on these items could range from 1 to 7 . Higher scores reflected greater influence of faculty colleagues and school administrators on subjects' perceptions of their influence on

Table 4 Cronbach alpha reliability coefficients of attitudes toward IPE and IPHCTs

\begin{tabular}{llllllll}
\hline Variables & $\mathbf{N U}$ & MD & PH & PT & OT & PA \\
& $(\mathbf{n = 1 9 1 )}$ & $(\mathbf{n = 3 8 )}$ & $\mathbf{( n = 4 6 )}$ & $\begin{array}{l}\mathbf{( n = 5 0 )} \\
(\mathbf{n}=\mathbf{4 0})\end{array}$ & $\begin{array}{l}\text { SW } \\
(\mathbf{n}=\mathbf{3 6})\end{array}$ \\
\hline Attitudes towards IPE & 0.92 & 0.91 & 0.89 & 0.88 & 0.90 & 0.93 & 0.93 \\
Attitudes towards IPHCTs & 0.90 & 0.90 & 0.85 & 0.90 & 0.86 & 0.88 & 0.85 \\
\hline
\end{tabular}

Abbreviations: NU, nursing; MD, allopathic medical schools; PH, pharmacy; PT, physical therapy; OT, occupational therapy; PA, physician assistant; SW, social work; IPE, interprofessional education; IPHCTs, interprofessional health-care teams. 
Table 5 Descriptive statistics of attitudes toward IPE, attitudes toward IPHCTs, subjective norms, and intent to engage in IPE

\begin{tabular}{|c|c|c|c|c|c|c|c|}
\hline Variables & $\begin{array}{l}\text { NU } \\
(n=191)\end{array}$ & $\begin{array}{l}\text { MD } \\
(n=38)\end{array}$ & $\begin{array}{l}\text { PH } \\
(n=46)\end{array}$ & $\begin{array}{l}\text { PT } \\
(n=50)\end{array}$ & $\begin{array}{l}\text { OT } \\
(n=40)\end{array}$ & $\begin{array}{l}\text { PA } \\
(n=38)\end{array}$ & $\begin{array}{l}\text { SW } \\
(n=36)\end{array}$ \\
\hline \multicolumn{8}{|c|}{ Attitudes toward IPE } \\
\hline \multicolumn{8}{|c|}{ Possible range (14-70) } \\
\hline Mean & 62.17 & 60.34 & 62.17 & 60.74 & 61.88 & 60.39 & 62.92 \\
\hline SD & 6.44 & 7.24 & 5.64 & 5.84 & 5.73 & 7.87 & 6.78 \\
\hline Range & $42-70$ & $4 I-70$ & $5 \mathrm{I}-70$ & $47-70$ & $5 \mathrm{I}-70$ & $37-70$ & $45-70$ \\
\hline Skew & -0.76 & -0.85 & -0.05 & 0.10 & -0.19 & -0.85 & -0.72 \\
\hline Kurtosis & 0.29 & 0.30 & -1.03 & -0.71 & -1.05 & 0.45 & 0.39 \\
\hline \multicolumn{8}{|c|}{ Attitudes toward IPHCTs } \\
\hline \multicolumn{8}{|c|}{ Possible range (14-70) } \\
\hline Mean & 56.05 & 55.63 & 56.41 & 54.88 & 55.65 & 55.79 & 58.36 \\
\hline SD & 7.11 & 7.10 & 5.85 & 6.97 & 6.42 & 7.32 & 6.43 \\
\hline Range & $29-70$ & $33-69$ & $44-70$ & $35-70$ & $45-70$ & $39-70$ & $44-70$ \\
\hline Skew & -0.21 & -0.64 & 0.11 & -0.01 & 0.44 & -0.52 & -0.24 \\
\hline Kurtosis & 0.65 & 1.84 & -0.50 & 0.39 & -0.23 & 0.09 & 0.39 \\
\hline \multicolumn{8}{|c|}{ My faculty colleagues think I should engage in IPE } \\
\hline \multicolumn{8}{|c|}{ Possible range $(\mathrm{I}-7)$} \\
\hline Mean & 5.74 & 5.45 & 5.96 & 5.90 & 5.92 & 6.13 & 6.06 \\
\hline SD & 1.57 & 1.57 & 1.38 & 1.40 & 1.40 & 1.56 & $\mathrm{I} .4 \mathrm{I}$ \\
\hline Range & $\mathrm{I}-7$ & $2-7$ & $1-7$ & $2-7$ & $2-7$ & $1-7$ & $2-7$ \\
\hline Skew & -0.98 & -0.36 & -1.40 & -1.18 & -1 & -2.20 & -1.21 \\
\hline Kurtosis & 0.06 & -1.37 & 2.04 & 0.70 & -0.15 & 4.66 & 0.37 \\
\hline \multicolumn{8}{|c|}{ My school's administrators think I should engage in IPE } \\
\hline \multicolumn{8}{|c|}{ Possible range (I-7) } \\
\hline Mean & 5.87 & 5.46 & 6.17 & 6.16 & 5.83 & 6.24 & 6.12 \\
\hline SD & 1.48 & 1.50 & 1.37 & 1.33 & 1.39 & 1.38 & 1.37 \\
\hline Range & $\mathrm{I}-7$ & $2-7$ & $1-7$ & $2-7$ & $2-7$ & $\mathrm{I}-7$ & $2-7$ \\
\hline Skew & -1.07 & -0.23 & -1.90 & -1.44 & -0.93 & -2.07 & -1.44 \\
\hline Kurtosis & 0.24 & -1.35 & 3.60 & 1.03 & -0.12 & 4.46 & 0.40 \\
\hline \multicolumn{8}{|c|}{ Intent to engage in IPE } \\
\hline \multicolumn{8}{|c|}{ Possible range $(I-10)$} \\
\hline Mean & 6.81 & 7.76 & 7.63 & 8.42 & 7.38 & 8.39 & 7.49 \\
\hline SD & 3.19 & 2.95 & 2.70 & 2.43 & 3.13 & 2.72 & 3.07 \\
\hline Range & $1-10$ & $1-10$ & $1-10$ & $2-10$ & $1-10$ & $1-10$ & $1-10$ \\
\hline Skew & -0.53 & -1.23 & -0.92 & -1.58 & -0.83 & -1.77 & -1.05 \\
\hline Kurtosis & -1.16 & 0.33 & -0.13 & 1.39 & -0.73 & 1.90 & -0.34 \\
\hline
\end{tabular}

Abbreviations: NU, nursing; MD, allopathic medical schools; PH, pharmacy; PT, physical therapy; OT, occupational therapy; PA, physician assistant; SW, social work; IPE, interprofessional education; IPHCTs, interprofessional health-care teams; SD, standard deviation.

engaging in IPE. The modal score was consistently 7 across all HCF groups for both items measuring SNs.

Minimum scores for whether faculty believed their faculty colleagues thought they should engage in IPE fell below the midpoint of 3.5 of the possible scores and had means that ranged from 5.45 to 6.13 (SD range 1.38-1.57). HCF believed that their faculty colleagues and school administrators thought they should engage in IPE; therefore, they perceived social pressure to engage in IPE.

Intentions were analyzed using a 10-point Likert scale. Possible scores ranged from 1 to 10 , with higher scores reflecting greater likelihood of engaging within IPE in the next 3 years. Mean scores ranged from 6.18 to 8.42 (SD range 2.43-3.19). All HCF groups had a mode of 10, and $35.4 \%-57.9 \%$ of HCF stated they were very likely to engage in or continue to engage in IPE within the next 3 years. Only $4.3 \%-9 \%$ indicated they were not likely to engage in IPE. Details of the descriptive statistical analysis for SNs and intentions are presented in Table 5.

Pearson correlations revealed that scores for the two SN variables - "My faculty colleagues think I should/should not engage in IPE" and "My school's administrators think I should/should not engage in IPE" - were significantly related to scores on intent to engage in IPE. Details of the Pearson correlations are presented in Table 6.

\section{Relationships among attitudes and intentions}

A stepwise multiple regression analysis was computed to examine relationships among HCF attitudes toward IPE, 
Table 6 Pearson correlations of subjective norms for faculty colleagues and subjective norms for school's administrators with intent to engage in IPE

\begin{tabular}{llll}
\hline $\begin{array}{l}\text { SN variables correlated } \\
\text { with intent to engage in IPE }\end{array}$ & $\boldsymbol{r}$ & $\boldsymbol{P}$ & $\boldsymbol{r}^{2}$ \\
\hline SN faculty colleagues & 0.43 & $<0.001$ & $18.5 \%$ \\
SN school's administrators & 0.52 & $<0.001$ & $27.0 \%$ \\
\hline
\end{tabular}

Abbreviations: IPE, interprofessional education; IPHCTs, interprofessional healthcare teams; $\mathrm{SN}$, subjective norm.

IPHCTs, and intent to engage in IPE. An initial Pearson correlation matrix revealed that both attitude variables were significantly but weakly related to intent to engage in IPE (Table 7). Multiple regression analysis revealed that attitudes toward IPE were the single best attitude predictor of intent to engage in IPE $(R=0.31, P<0.001)$ but only explained $9.5 \%$ of the variance in intent to engage in IPE scores.

Attitudes toward IPHCTs alone explained 5.3\% of the variance in intent to engage in IPE scores. However, attitudes toward IPE and attitudes toward IPHCTs were significantly related $(r=0.75, P<0.001)$ and shared $56.3 \%$ of the variance in their scores. The two predictor variables were strongly correlated, demonstrating multicollinearity. Attitudes toward IPHCTs failed to enter the regression equation because this did not correlate well with and was not a good predictor of intent to engage in IPE, and was strongly related to attitudes toward IPE. Stepwise multiple regression analysis did not yield any more information than the simple Pearson correlations in this statistical analysis. Details of the stepwise multiple regression analysis are presented in Table 8 .

\section{Differences among HCF groups}

A multivariate analysis of variance (MANOVA) was computed to explore differences in attitudes toward IPE and IPHCTs among HCF from various professional health-care programs. The seven groups of faculty had relatively equal means for both instruments, with a range of 60.34-62.92 for attitudes toward IPE and a range of 54.88-58.36 for attitudes toward IPHCTs.

Table 7 Pearson correlations of attitudes with intent to engage in IPE

\begin{tabular}{llll}
\hline $\begin{array}{l}\text { Variables correlated } \\
\text { with intent to engage in IPE }\end{array}$ & $\boldsymbol{r}$ & $\boldsymbol{P}$ & $\boldsymbol{r}^{2}$ \\
\hline Attitudes toward IPE & $0.3 \mathrm{I}$ & $<0.00 \mathrm{I}$ & $9.5 \%$ \\
Attitudes toward IPHCTs & 0.23 & $<0.00 \mathrm{I}$ & $5.3 \%$ \\
\hline
\end{tabular}

Abbreviations: IPE, interprofessional education; IPHCTs, interprofessional healthcare teams.
Table 8 Stepwise multiple regression of health-care faculty attitudes toward IPE, attitudes toward IPHCTs, and intent to engage in IPE

\begin{tabular}{lllllll}
\hline Model & $\boldsymbol{R}$ & $\boldsymbol{R}^{2}$ & $\boldsymbol{R}^{2} \boldsymbol{\Delta}$ & $\mathbf{F}$ & $\mathbf{d f}$ & $\boldsymbol{P}$ \\
\hline Attitudes toward IPE & $0.3 \mathrm{I}$ & 0.095 & 0.095 & 45.72 & $\mathrm{I} 434$ & $<0.00 \mathrm{I}$ \\
\hline $\begin{array}{l}\text { Abbreviations: IPE, interprofessional education; IPHCTs, interprofessional health- } \\
\text { care teams. }\end{array}$
\end{tabular}

Differences among the seven HCF groups on attitudes toward IPE were not significant $(P=0.356)$. Differences among the seven HCF groups on attitudes toward IPHCTs were not significant either $(P=0.438)$. These results indicated there were no significant differences among the groups of faculty regarding attitudes toward IPE or IPHCTs (Wilks' lambda $=0.294)$. Details of the MANOVA analysis are presented in Table 9.

Independent $t$-tests were computed to compare teaching faculty and administrative faculty scores on the research variables attitudes toward IPE, attitudes toward IPHCTs, intent to engage in IPE, beliefs that faculty colleagues think HCF should engage in IPE (SN colleagues), and beliefs that school administrators think faculty should engage in IPE (SN administrators). There were statistically significant differences on intent to engage in IPE, SN colleagues, and $\mathrm{SN}$ administrators. Independent $t$-tests were also computed to compare HCF who were currently engaged in IPE and those who were not, and between those HCF who were previously engaged in IPE and those who were not for all research variables. There were statistically significant differences among the groups for all variables. Details of the $t$-test analyses are presented in Table 10.

Pearson correlations were computed for age, years experience as a health professional, and years experience as a health-professional educator for the research variables attitudes toward IPE, attitudes toward IPHCTs, SN faculty colleagues, SN school administrators, and intent to engage in IPE. None of the correlations were statistically significant.

Based on independent $t$-tests, there were no statistically significant differences between males and females or among the groups on employment status, current faculty position, or

Table 9 Multivariate analysis of variance comparing seven disciplines of health-care faculty on attitudes toward IPE and attitudes toward IPHCTs

\begin{tabular}{llll}
\hline Variable & $\mathbf{F}$ & $\mathbf{d f}$ & $\mathbf{P}$ \\
\hline Attitudes toward IPE & I.II & 6432 & 0.356 \\
Attitudes toward IPHCTs & 0.98 & 6432 & 0.438 \\
\hline
\end{tabular}

Abbreviations: IPE, interprofessional education; IPHCTs, interprofessional healthcare teams. 
Table 10 Results of $t$-test analyses comparing groups from demographic variables on the research variables

\begin{tabular}{|c|c|c|c|c|c|c|c|}
\hline Research variable & Demographic variable and groups & $\mathbf{n}$ & M & SD & $t$ & df & $P$ \\
\hline \multirow[t]{6}{*}{ Attitudes toward IPE } & Currently engaged in IPE & & & & 5.36 & 371.69 & $<0.001$ \\
\hline & Yes & 248 & 63.16 & 5.80 & & & \\
\hline & No & 191 & 59.85 & 6.83 & & & \\
\hline & Previously engaged in IPE & & & & 3.49 & 367.25 & 0.001 \\
\hline & Yes & 249 & 62.67 & 6.01 & & & \\
\hline & No & 186 & 60.47 & 6.87 & & & \\
\hline \multirow[t]{6}{*}{ Attitudes toward IPHCTs } & Currently engaged in IPE & & & & 4.41 & 443 & $<0.001$ \\
\hline & Yes & 248 & 57.29 & 6.73 & & & \\
\hline & No & 191 & 54.43 & 6.75 & & & \\
\hline & Previously engaged in IPE & & & & 2.91 & 433 & 0.004 \\
\hline & Yes & 249 & 56.89 & 6.86 & & & \\
\hline & No & 186 & 54.97 & 6.81 & & & \\
\hline \multirow{6}{*}{ Intent to engage in IPE } & Position & & & & -2.60 & 118.48 & 0.010 \\
\hline & Teaching & 356 & 7.26 & 3.10 & & & \\
\hline & Administrative & 71 & 8.14 & 2.47 & & & \\
\hline & Currently engaged in IPE & & & & 14.79 & 310.15 & $<0.001$ \\
\hline & Yes & 246 & 8.99 & 1.95 & & & \\
\hline & No & 190 & 5.32 & 2.96 & & & \\
\hline \multirow[t]{3}{*}{ Intent to engage in IPE } & Previously engaged in IPE & & & & 9.36 & 336.80 & $<0.001$ \\
\hline & Yes & 248 & 8.48 & 2.46 & & & \\
\hline & No & 184 & 5.87 & 3.13 & & & \\
\hline \multirow[t]{9}{*}{ SN colleagues } & Position & & & & -2.09 & 112.10 & 0.039 \\
\hline & Teaching & 343 & 5.77 & 1.54 & & & \\
\hline & Administrative & 71 & 6.14 & 1.33 & & & \\
\hline & Currently engaged in IPE & & & & 9.74 & 296.63 & $<0.00$ I \\
\hline & Yes & 243 & 6.42 & 1.09 & & & \\
\hline & No & 181 & 5.06 & 1.63 & & & \\
\hline & Previously engaged in IPE & & & & 7.21 & 303.55 & $<0.001$ \\
\hline & Yes & 245 & 6.27 & 1.22 & & & \\
\hline & No & 175 & 5.21 & 1.65 & & & \\
\hline \multirow[t]{9}{*}{$\mathrm{SN}$ administrators } & Position & & & & -3.72 & 133.33 & $<0.001$ \\
\hline & Teaching & 346 & 5.85 & 1.49 & & & \\
\hline & Administrative & 71 & 6.41 & 1.06 & & & \\
\hline & Currently engaged in IPE & & & & 10.99 & 280.15 & $<0.001$ \\
\hline & Yes & 247 & 6.55 & 0.97 & & & \\
\hline & No & 180 & 5.12 & 1.55 & & & \\
\hline & Previously engaged in IPE & & & & 7.30 & 315.65 & $<0.001$ \\
\hline & Yes & 247 & 6.36 & 1.19 & & & \\
\hline & No & 176 & 5.35 & 1.54 & & & \\
\hline
\end{tabular}

Abbreviations: IPE, interprofessional education; IPHCTs, interprofessional health-care teams; SN, subjective norm; SD, standard deviation.

highest level of education for scores on any of the research variables. Independent $t$-tests also revealed that there were no statistically significant differences between teaching faculty and administrative faculty for attitudes toward IPE, attitudes toward IPHCTs, SN faculty colleagues, or SN school administrators.

ANOVAs were computed to compare the various faculty ranks and tenure status for all attitudes, SNs, and intent to engage in IPE research variables. There were no statistically significant differences among any of the faculty rank or tenure groups.

A MANOVA was computed to explore differences among the seven HCF groups on SN faculty colleagues and SN school administrators. Results indicated there were no significant differences among the groups of faculty on SN faculty colleagues and SN school administrators.

\section{HCF intent to engage in IPE based on attitudes and $\mathrm{SNs}$}

A multiple regression analysis was computed to regress the two attitude variables and the two $\mathrm{SN}$ variables on intent to engage in IPE scores. The analysis revealed that SN school administrators was the best predictor of and explained $26.6 \%$ of the variance in intent to engage in IPE. Attitudes toward IPE was the next significant predictor and added an additional $2.7 \%$ explanation of variance (Table 11). Thus, a total of $29.3 \%$ of the variance in intent to engage in IPE was 
Table II Stepwise multiple regression of health care faculty attitudes toward IPE, attitudes toward IPHCTs, subjective norms for faculty colleagues, subjective norms for school administrators, and intent to engage in IPE

\begin{tabular}{lllllll}
\hline Model & $\boldsymbol{R}$ & $\boldsymbol{R}^{2}$ & $\boldsymbol{R}^{2} \boldsymbol{\Delta}$ & $\mathbf{F}$ & $\mathbf{d f}$ & $\boldsymbol{P}$ \\
\hline $\begin{array}{l}\text { Subjective norms - } \\
\text { school administrators }\end{array}$ & 0.52 & 0.266 & 0.266 & 151.40 & 1417 & $<0.00 \mathrm{I}$ \\
$\begin{array}{l}\text { Attitudes toward IPE } \\
0.54\end{array}$ & 0.293 & 0.027 & 15.96 & 1416 & $<0.00 \mathrm{I}$ \\
\hline
\end{tabular}

Abbreviations: IPE, interprofessional education; IPHCTs, interprofessional healthcare teams.

explained by the linear combination of one $\mathrm{SN}$ and one attitude variable $(R=0.54, P<0.001)$. Attitudes toward IPHCTs and $\mathrm{SN}$ faculty colleagues failed to enter the equation.

\section{Discussion}

According to O'Keefe, ${ }^{25}$ attitudes are a significant predictor of behavioral intent. Based on the theoretical model of TRA, attitudes were proposed to influence intentions to deliver IPE to health-care professional students. Social work faculty had the highest mean of the HCF groups for both attitudes toward IPE and attitudes toward IPHCTs. Social workers are typically required to cooperate and collaborate with other health professionals as part of a health-care team. ${ }^{4}$ As social workers seek to promote positive change for patients through the acquiring of services and resources, they often interact with many other types of professionals. Medicine faculty had the lowest mean on attitudes toward IPE. Traditionally, physicians have been the dominant members of health-care teams. This is true in many countries, including the US, where nurses have been seen as subordinates..$^{26}$ Perhaps this is due to the "captain of the ship" role physicians have traditionally held, where they have been ultimately responsible for patients' outcomes and seen as being "at the helm."27

Physical therapy faculty had the lowest mean on attitudes toward IPHCTs. Physical therapists have generally worked as part of interprofessional teams, especially rehabilitative teams. There is no published literature to support an explanation for why they would exhibit the lowest IPHCT mean scores of the seven types of HCF.

HCF experience with IPE for the entire sample varied between 0 and 5 years. Experience with IPHCTs, however, did not vary greatly among the groups. Most HCF (56.5\%) stated they had more than 5 years experience with IPHCTs. Therefore, most of the HCF had several years of experience to draw from to form their opinions about IPE and IPHCTs.

Plausible explanations for the positive attitudes reported by subjects in this study may be that the scores could be, in part, due to a nonresponse error. ${ }^{20} \mathrm{~A}$ nonresponse error occurs when subjects selected by the researcher for a survey sample do not complete the survey because they may not be interested in the topic. The nonresponders' survey answers may have been different from those who did respond. HCF who were not interested in IPE, or who held negative attitudes toward IPE and IPHCTs, may have ignored or deleted the survey, and so this study may be missing what could have been negative responses.

Intent to engage in IPE is HCF's determination to act on and become involved in IPE. On average, HCF indicated they were very likely to engage in or continue to engage in IPE within the next 3 years.

HCF demonstrated positive attitudes toward IPE, positive attitudes toward IPHCTs, and believed that their faculty colleagues and school administrators thought they should engage in IPE. Within the TRA model, the combination of attitudes and SNs predict behavioral intentions. In this case, together they predict the intention to engage in IPE or continue to engage in IPE.

IPE is an undertaking that requires curricular integration, scheduling, time, and effort that is beyond the control of any one HCF member. HCF volitional control or control over their own behaviors with regard to IPE implementation may be difficult, if not impossible, to achieve. Engaging in IPE is not an individual decision; it requires system-wide changes and support.

Given that HCF groups demonstrated positive attitudes towards IPE, the question "Why aren't more HCF currently engaging in IPE?" remains unanswered. Within TRA, behavior is not as well explained as intent to behave. This is due to the recognition that situational factors may limit behavioral actions, even when a strong positive attitude and desire to behave is present.

Faculty intentions to engage in IPE were proposed to be a result of the combined influence of attitudes toward IPE and attitudes toward IPHCTs. Attitudes toward IPE were found to be the single best attitude predictor of intent to engage in IPE.

TRA research has shown that attitude is a very strong predictor of behavior. ${ }^{25}$ However, the correlations in this study, although statistically significant, were weak. Perhaps the colleges and universities where HCF were employed were not requiring, or even encouraging, IPE.

The seven HCF groups in this study did not differ significantly on attitudes toward IPE or IPHCTs. Over the past few years, medicine has become very proactive with regard to IPE implementation. This may have contributed to the MD group's positive attitudes toward IPE. Currently, according to this study's results, MD faculty are implementing IPE at the 
highest rate, while nursing is implementing it at the lowest rate. Barker et $\mathrm{al}^{28}$ suggested that regulation of medical education and support for IPE from the medicine accrediting bodies may facilitate a positive shift in perception of IPE in MD faculty.

Accrediting bodies for most of the HCF groups in this study require interprofessional teamwork and collaboration as part of their guidelines. Accreditation requirements, in addition to the positive benefits of IPE described in the literature, may explain why all HCF groups in this study demonstrated positive attitudes toward IPE and IPHCTs.

The fact that HCF indicated strong positive attitudes toward IPE and IPHCTs, strong SNs, and strong intent to engage or continue to engage in IPE over the next 3 years may also be due in part to social desirability and acquiescence. ${ }^{20}$ Social desirability happens when subjects answer questions based on what they know the researcher is hoping to hear. Acquiescence happens when subjects tend to agree with others. Acquiescence is a function of SNs. HCF, in response to the influence from SN faculty colleagues and SN school administrators, may perceive and report that they should engage in IPE because they feel they should be in agreement with their peers and organizational leaders. Social desirability and acquiescence should be considered when explaining why subjects reported strong positive attitudes toward IPE and IPHCTs, beliefs that their faculty colleagues and school administrators think they should engage in IPE, and strong intent to engage or continue to engage in IPE over the next 3 years, yet are not actually implementing IPE in their curricula.

Scores on the two SN variables - "My faculty colleagues think I should/should not engage in IPE" and "My school's administrators think I should/should not engage in IPE" were significantly related to scores on intent to engage in IPE. Analysis revealed that SN school administrators was the single best predictor and the combination of SN school administrators plus attitudes toward IPE was the best multiple regression predictor of intent to engage in IPE. While research based on TRA has shown attitude is a stronger and more accurate predictor of behavior than $\mathrm{SNs}^{25}$ the data from the current research refutes this previous conclusion. In this study, SNs were stronger and better predictors of intention than attitudes. This outcome is consistent with and supportive of TRA, since it was the combination of attitude and SNs that was the best predictor of intent. The application of the TRA model based on statistical findings in this study is presented in Figure 1. All correlations presented were statistically significant. The linear combination of the best predictors is emphasized in bold type.

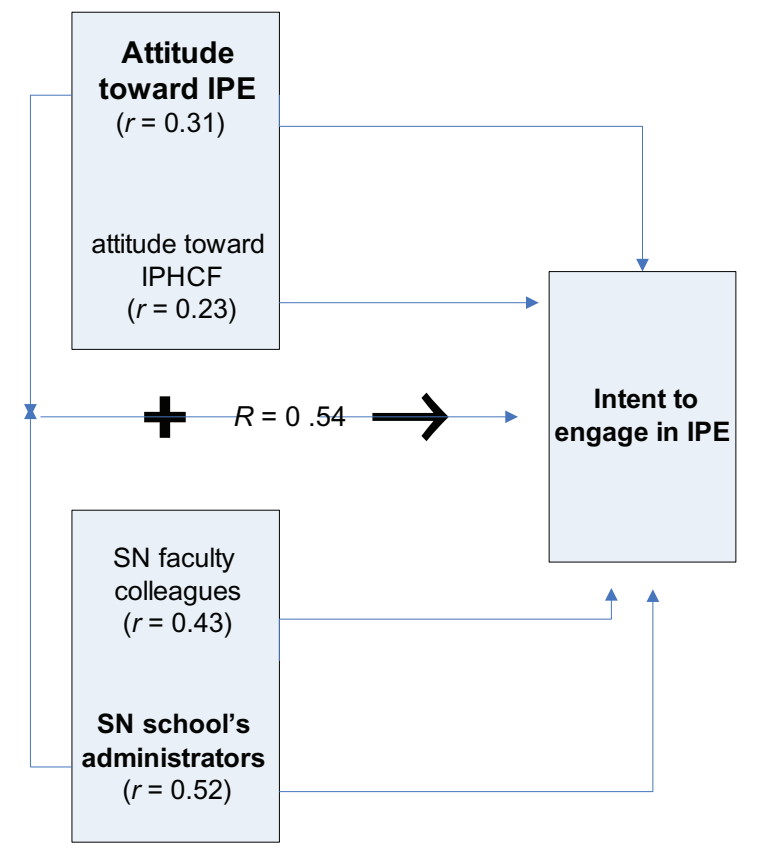

Figure I Revised application of the theory of reasoned action model based on study findings.

Abbreviations: IPE, interprofessional education; IPHCTs, interprofessional healthcare teams; SN, subjective norm.

These findings are consistent with the meta-analysis by Wallace et al, ${ }^{29}$ which found that social pressures or SNs moderated the relationship between attitudes and behavior. When behaviors were desirable and politically correct, people tended to perform the behaviors. Attitudes predicted behaviors better when there were weak social pressures surrounding the situation.

Administrative faculty reported they were more likely to intend to engage in IPE than teaching faculty. This may be due, in part, to administrators being more involved in accreditation processes and having greater awareness of the IPE requirements of accrediting bodies. It is also possible that administrative faculty are more acutely aware of IOM recommendations, since they are more likely to be responsible for carrying them out.

$\mathrm{HCF}$ who were currently engaged in IPE or previously engaged in IPE had more positive attitudes toward IPE and IPHCTs, were more likely to engage or continue to engage in IPE, and had beliefs that their faculty colleagues and school's administrators believed they should engage in IPE.

Age, years experience as a health-care professional, and years experience as a health-professional educator are not related to any of the research variables. Findings regarding $\mathrm{HCF}$ age and experience suggest that HCF should not meet generational resistance in implementation of IPE, since all ages of faculty were supportive of IPE. This is a positive 
interpretation and should facilitate IPE implementation. Current faculty position, faculty rank, and tenure did not influence attitudes, SNs, or intent to engage in IPE. Future research on IPE should include all HCF.

\section{Generalizability of the findings}

Generalizability of this study's findings is limited to a sample of the seven health-care professional groups, who were primarily female, doctorally prepared and between the ages of 46 and 54 years. Generalizability is also limited to primarily full-time, nontenured, and assistant and associate professors with an average of 20-31 years of health-professional experience and 11-17 years of experience as a health-professional educator.

\section{Study limitations}

Subjects included primarily only full time, professorial ranked faculty. Subjects included only HCF with publicly available email addresses on their school or educationprogram website.

\section{Conclusion}

We drew several conclusions based on the findings of this study. HCF have positive attitudes toward IPE and IPHCTs. There were no differences in attitudes toward IPE or IPHCTs among HCF. However, overall, HCF have generally less positive attitudes about IPHCTs than they do about IPE. Most HCF report that they are very likely to engage in IPE or continue to engage in IPE within the next 3 years. Administrative faculty are more likely to engage or continue to engage in IPE than teaching faculty.

HCF believe their faculty colleagues ( $\mathrm{SN}$ faculty colleagues) and school administrators ( $\mathrm{SN}$ school administrators) think they should engage in IPE. HCF who are currently engaged in IPE or have previously been engaged in IPE have better attitudes toward IPE and IPHCTs, and are more likely to engage in or continue to engage in IPE. HCF report that their faculty colleagues and school administrators believe they should engage in IPE. The combination of social pressure from school administrators and attitudes toward IPE predict intent to engage in IPE better than any one variable alone.

There were no statistically significant differences between teaching faculty and administrative faculty on attitudes toward IPE, attitudes toward IPHCTs, intent to engage in IPE, SN colleagues, or SN administrators. There were no statistically significant differences among age, sex, employment status, current faculty position, highest level of education, years experience as a health-care professional, or years experience as a health-professional educator on the research variables.

\section{Recommendations for future research}

As a result of this study, the following recommendations for future research are suggested. Replicate this study based on the TRA model measuring HCF actual engagement in IPE. Explore IPE and IPHCTs in relation to actual patient outcomes. If patient safety, quality of care, and enhanced patient outcomes can be linked to IPE, this would begin to build a base of empirical literature to support its incorporation into the health-care professional curriculum. Explore HCF perceptions of SNs concerning accreditation requirements. Identify strategies that are most effective in eliminating barriers and negative factors related to IPE. Identify strategies for effective IPE implementation. Investigate faculty attitudes in countries outside the US where socialized medicine and health-care exist and where IPE seems to flourish. Identify health-care professional attitudes (those who are employed in health-care and not teaching) toward IPE and IPHCTs, and determine if they differ from faculty attitudes, since full-time faculty may not be actively practicing.

Lastly, in future research, include all faculty, not just fulltime ranked professors, since lecturers and adjunct faculty may also play a role in curricular decision-making.

\section{Disclosure}

The authors have no potential conflicts of interest, including financial and/or personal relationships that might bias their work.

\section{References}

1. Committee on Quality Healthcare in America and Institute of Medicine. To Err Is Human: Building a Safer Health System. Washington: National Academies Press; 1999.

2. Committee on Quality Healthcare in America and Institute of Medicine. Crossing the Quality Chasm: A New Health System for the 21st Century. Washington: National Academies Press; 2001.

3. Greiner AC, Knebel E, editors. Health Professions Education: A Bridge to Quality. Washington: National Academies Press; 2003.

4. Committee on the Robert Wood Johnson Foundation Initiative on the Future of Nursing at the Institute of Medicine. The Future of Nursing: Leading Change, Advancing Health. Washington: National Academies Press; 2010.

5. Yan J, Gilbert JHV, Hoffman SJ. World Health Organization study group on interprofessional education and collaborative practice. J Interprof Care. 2007;21:588-589.

6. World Health Organization (WHO). Framework for Action on Interprofessional Education and Collaborative Practice. Geneva: WHO; 2010. Available from: http://whqlibdoc.who.int/hq/2010/WHO_HRH_ HPN_10.3_eng.pdf. Accessed June 20, 2012.

7. Wilcock PM, Janes G, Chambers A. Health care improvement and continuing interprofessional education: continuing interprofessional development to improve patient outcomes. $J$ Contin Educ Health Prof. 2009;29:84-90. 
8. Gilbert JH. Abraham Flexner and the roots of interprofessional education. J Contin Educ Health Prof. 2008;28 Suppl 1:S11-S14.

9. Williams RG, Silverman R, Schwind C, et al. Surgeon information transfer and communication: factors affecting quality and efficiency of inpatient care. Ann Surg. 2007;245:159-169.

10. Rosenstein AH, O'Daniel M. Impact and implications of disruptive behavior in the perioperative arena. $J$ Am Coll Surg. 2006;203: 96-105.

11. Lingard L, Espin S, Evans C, Hawryluck L. The rules of the game: interprofessional collaboration on the intensive care unit team. Crit Care. 2004;8:R403-R408.

12. Olenick M, Allen LR, Smego RA. Interprofessional education: a concept analysis. Adv Med Educ Pract. 2010;1:1-10.

13. Zwarenstein M, Goldman J, Reeves S. Interprofessional collaboration effects of practice-based interventions on professional practice and healthcare outcomes. Cochrane Database Syst Rev. 2009;3: CD000072.

14. Hammick M, Freeth D, Koppel I, Reeves S, Barr H. A best evidence systematic review of IPE: BEME Guide no 9. Med Teach. 2007;8: 735-751.

15. Hyer K, Fairchild S, Abraham I, Mezey M, Fulmer T. Measuring attitudes related to interdisciplinary training: revisiting the Heinemann, Schmitt and Farrell attitudes toward health care teams scale. J Interprof Care. 2000;14:249-258.

16. Fishbein M, Ajzen I. Belief, Attitude, Intention, and Behavior. Reading (MA): Addison-Wesley; 1975.

17. Sheppard BH, Hartwick J, Warshaw PR. The theory of reasoned action: a meta-analysis of past research with recommendations for modifications and future research. J Consum Res. 1988;15:325-343.

18. Ajzen I, Madden TJ. Prediction of goal directed behavior: attitudes, intentions, and perceived behavioral control. J Exp Soc Psychol. 1986; 22:453-474.
19. United States Census Bureau. Census regions and divisions of the United States. Available from: http://www.census.gov/geo/www/us_regdiv. pdf. Accessed June 20, 2012.

20. Dillman DA, Smyth JD, Melani Christian L 3rd, editors. Internet, Mail, and Mixed Mode Surveys: The Tailored Design Method. Hoboken (NJ): John Wiley \& Sons; 2009.

21. SPSS. Sample Power (release 2.0). Chicago: SPSS; 2004.

22. Curran VR, Sharpe D, Forristall J, Flynn K. Attitudes of health sciences students towards interprofessional teamwork and education. Med Educ. 2008;7:146-156.

23. Parsell G, Bligh J. The development of a questionnaire to assess the readiness of health care students for interprofessional learning (RIPLS). Med Educ. 1991;33:95-100.

24. Heinemann GD, Schmitt MH, Farrell MP. Attitudes toward healthcare teams. In: Heinemann GD, Zeiss AM, editors. Team Performance in Healthcare: Assessment and Development. New York: Kluwer Academic/Plenum; 2002:155-159.

25. O'Keefe DJ. Persuasion: Theory and Research. Newbury Park (CA) Sage; 1990.

26. Dimitriadou A, Lavdaniti M, Theofanidis D, et al. Interprofessional collaboration and collaboration among nursing staff members in Northern Greece. Int J Caring Sci. 2008;1:140-146.

27. Tabby DS. Where is the "captain of the ship"? J Am Osteopath Assoc. 2009;7:386-387.

28. Barker KK, Bosco C, Oandasan IF. Factors in implementing interprofessional education and collaborative practice initiatives: findings from key informant interviews. J Interprof Care. 2005;19 Suppl 1: 166-176.

29. Wallace DS, Paulson RM, Lord CG, Bond CF Jr. Which behaviors do attitudes predict? Meta-analyzing the effects of social pressure and perceived difficulty. Rev Gen Psychol. 2005;9:214-227.
Journal of Multidisciplinary Healthcare

\section{Publish your work in this journal}

The Journal of Multidisciplinary Healthcare is an international, peerreviewed open-access journal that aims to represent and publish research in healthcare areas delivered by practitioners of different disciplines. This includes studies and reviews conducted by multidisciplinary teams as well as research which evaluates the results or conduct of such teams or

\section{Dovepress}

healthcare processes in general. The journal covers a wide range of areas and welcomes submission from practitioners at all levels, from all over the world. The manuscript management system is completely online and includes a very quick and fair peer-review system. Visit http://www.dovepress.com/testimonials.php to read real quotes from published authors. 